\title{
Smart plastic functionalization by nanoimprint and injection molding
}

Zalkovskij, Maksim; Thamdrup, Lasse Højlund; Smistrup, Kristian; Andén, Thomas; Johansson, Alicia C.; Mikkelsen, Niels Jørgen; Madsen, Morten Hannibal; Garnæs, Jørgen; Kristiansen, Tommy Tungelund; Diemer, Mads

Total number of authors:

18

Published in:

Proceedings of SPIE

Link to article, DOI:

10.1117/12.2085766

Publication date:

2015

Document Version

Publisher's PDF, also known as Version of record

Link back to DTU Orbit

Citation (APA):

Zalkovskij, M., Thamdrup, L. H., Smistrup, K., Andén, T., Johansson, A. C., Mikkelsen, N. J., Madsen, M. H. Garnæs, J., Kristiansen, T. T., Diemer, M., Døssing, M., Minzari, D., Tang, P. T., Kristensen, A., Taboryski, R. J., Essendrop, S., Nielsen, T., \& Bilenberg, B. (2015). Smart plastic functionalization by nanoimprint and injection molding. In Proceedings of SPIE (Vol. 9423). SPIE - International Society for Optical Engineering. Proceedings of SPIE - The International Society for Optical Engineering https://doi.org/10.1117/12.2085766

\section{General rights}

Copyright and moral rights for the publications made accessible in the public portal are retained by the authors and/or other copyright owners and it is a condition of accessing publications that users recognise and abide by the legal requirements associated with these rights.

- Users may download and print one copy of any publication from the public portal for the purpose of private study or research.

- You may not further distribute the material or use it for any profit-making activity or commercial gain

- You may freely distribute the URL identifying the publication in the public portal 


\title{
Smart plastic functionalization by nanoimprint and injection molding
}

\author{
Maksim Zalkovskij ${ }^{* a}$, Lasse H. Thamdrup ${ }^{\mathrm{a}}$, Kristian Smistrup ${ }^{\mathrm{a}}$, Thomas Andén ${ }^{\mathrm{a}}$, Alicia C. \\ Johansson $^{\mathrm{a}}$, Niels Jørgen Mikkelsen ${ }^{\mathrm{b}}$, Morten Hannibal Madsen ${ }^{\mathrm{c}}$, Jørgen Garnæs ${ }^{\mathrm{c}}$, Tommy \\ Tungelund Kristiansen ${ }^{\mathrm{d}}$, Mads Diemer ${ }^{\mathrm{d}}$, Michael Døssing ${ }^{\mathrm{e}}$, Daniel Minzari ${ }^{\mathrm{f}}$, Peter Torben Tang ${ }^{\mathrm{f}}$, \\ Anders Kristensen $^{\mathrm{g}}$, Rafael Taboryski ${ }^{\mathrm{g}}$, Søren Essendrop ${ }^{\mathrm{h}}$, Theodor Nielsen ${ }^{\mathrm{a}}$ and Brian Bilenberg*a \\ ${ }^{a}$ NIL Technology ApS, Diplomvej 381, DK-2800 Kongens Lyngby, Denmark; ${ }^{\mathrm{b}}$ CemeCon \\ Scandinavia, Lokesvej 5, DK-8230 Aarhus, Denmark; ${ }^{\mathrm{C} D F M ~ A / S, ~ M a t e m a t i k t o r v e t ~ 307, ~ D K-2800 ~}$ \\ Kongens Lyngby, Denmark; ${ }^{\mathrm{d} L E G O}$ System A/S, Åstvej 1, DK-7190 Billund, Denmark; ${ }^{\mathrm{e}} \mathrm{TOOL}$ \\ Partners, Vilhelmsborgvej 5, DK-7700 Thisted, Denmark; ${ }^{f}$ IPU, Nils Koppels Alle, Building 404, \\ DK-2800 Kongens Lyngby, Denmark; ' DTU Nanotech, Ørsteds Plads, Building 345E, DK-2800 \\ Kongens Lyngby, Denmark; ${ }^{\mathrm{h}}$ SE Design, Sundvej 16b, st. tv., DK-2900 Hellerup, Denmark
}

\begin{abstract}
In this paper, we present a route for making smart functionalized plastic parts by injection molding with sub-micrometer surface structures. The method is based on combining planar processes well known and established within silicon micro and sub-micro fabrication with proven high resolution and high fidelity with truly freeform injection molding inserts. The link between the planar processes and the freeform shaped injection molding inserts is enabled by the use of nanoimprint with flexible molds for the pattern definition combined with unidirectional sputter etching for transferring the pattern. With this approach, we demonstrate the transfer of down to $140 \mathrm{~nm}$ wide holes on large areas with good structure fidelity on an injection molding steel insert. The durability of the sub-micrometer structures on the inserts have been investigated by running two production series of 102,000 and 73,000 injection molded parts, respectively, on two different inserts and inspecting the inserts before and after the production series and the molded parts during the production series.
\end{abstract}

Keywords: nanoimprint, injection molding, plastic, sub-micro structures, surface functionalization

\section{INTRODUCTION}

Injection molding of plastic parts is a widely used high volume production technique, which is used to produce more and more of the devices we are using in daily life, from mobile phones and TVs to food packaging, and blue ray and DVD discs. Due to the high volumes capable of injection molding the price per part is low, and in order to stay competitive in the market, the vendors prefer to get as many new functionalities as possible integrated into the molding process because additional handling will increase the price per part many fold. Being able to modify a surface with specifically designed micro- and nano-patterns, enables extraordinary surface properties such as, self-cleaning ${ }^{1}$, strong-adhesion (gecko effect) $)^{2}$, super-hydrophobic ${ }^{1}$, change of friction (shark skin) ${ }^{3}$ and decoration by optical diffraction or plasmonics ${ }^{4}$. Particularly coloration by optical diffractive or plasmonic nano structures have gained a massive interest from the industry due to the wide range of color effects that can be obtained without any use of pigments in the plastic and without additional decoration processes. These effects are typically inspired by nature like the surface of lotus leafs that shows superior self-cleaning properties or the wings of butterflies that are showing distinct colors due to structures and not pigments. Nature is very advanced and the effects found in nature are often relying on very complex structures and geometries so one has to put efforts into simplifying the structures making them producible and still maintain a decent functionality. This "inspired by nature and designed for manufacturability" approach is depicted artistically in Figure 1. Several techniques are available today that allows for nanostructuring of surfaces such as electron beam lithography,

*bb@nilt.com; phone +45 3171 9037; fax +45 7014 1916; nilt.com

Alternative Lithographic Technologies VII, edited by Douglas J. Resnick, Christopher Bencher, Proc. of SPIE Vol. 9423, 94230T - ( c 2015 SPIE - CCC code: 0277-786X/15/\$18 doi: $10.1117 / 12.2085766$ 
deep ultraviolet lithography and nanoimprint lithography ${ }^{5}$. Electron beam lithography and deep ultraviolet lithography are only directly applicable on planar surfaces and typically only on wafer type substrates. Nanoimprint lithography is also most often used on planar surfaces but with some modifications and with the use of flexible mold materials it is possible to do nanoimprint on freeforms. Ultimately when doing NIL on freeforms one have to consider the bending and stretching of the flexible mold ${ }^{6}$ but this has not been considered in the work presented here. In this paper, we present the process flow for making steel injection molding inserts with sub-micrometer structures besides initial insert lifetime results and early results regarding the ultimate resolution of the process flow. An optical diffraction pattern with line gratings of periods from $700 \mathrm{~nm}$ to $1400 \mathrm{~nm}$ are used to demonstrate the process flow since such a pattern is easy to visualize and somewhat easy to inspect. For decoration by plasmonic structures and some approaches for super hydrophobic and self-cleaning surfaces as well as more advanced applications within among others the biotech and pharma sectors much denser patterns are needed. Thus, the possibility of achieving this with the presented technology is briefly discussed at the end of the paper.

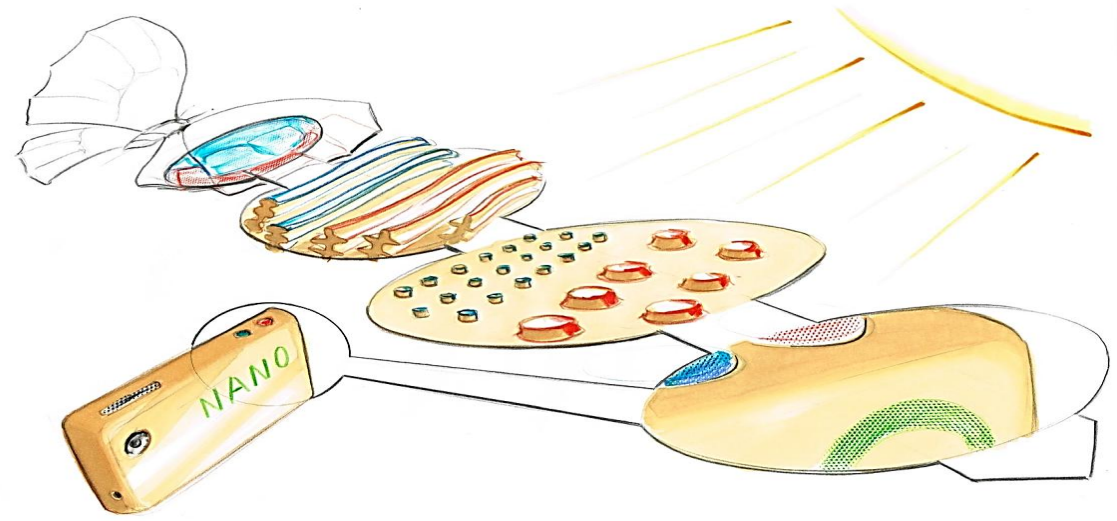

Figure 1. Nano patterned colouring “inspired by nature and designed for manufacturability”.

\section{FABRICATION OF INJECTION MOLDING INSERTS WITH SUB-MICRO STRUCTURES}

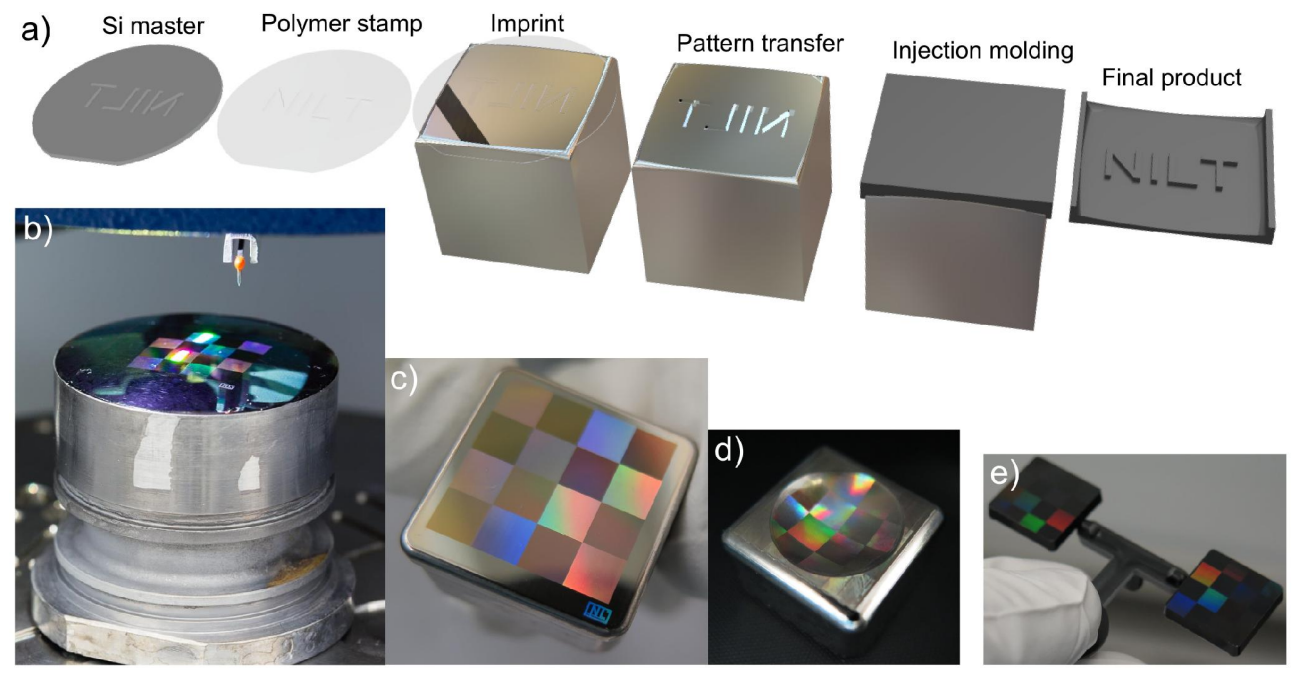

Figure 2. a) Process flow for making injection molding inserts with sub-micrometer structures (also the injection molding process and the final plastic part are shown), b)-d) examples of different insert formats we have demonstrated submicrometer pattern transfer on, e) Example of an injection molded part made with the insert shown in c). 
The starting point is a planer master made with electron beam lithography or deep ultraviolet lithography and dry etching. In the presented work we use a master with a 4 x 4 array, see Figure 3.a, of optical diffraction gratings with a pitch from $700 \mathrm{~nm}$ to $1400 \mathrm{~nm}$, duty cycle $50 \%$, and with varying linegrating orientations to ensure a clear diffractive response from some grating fields independent of the viewing angle. A flexible mold is made as a copy of the silicon master so it will have the opposite polarity of the master. In this work both a single material flexible mold and a hybrid flexible mold with a hard glass like surface and a soft backbone has been used. The flexible mold copies are made in a modified CNI tool ${ }^{7}$. The injection molding insert to be structured is made in steel and is polished to a surface quality of $\mathrm{Aq} \sim 3$. Aq is described by an optical method where a characteristic value of the scattered light is measured for a given surface. For comparison, an Aq value of 0.7 is obtained for a polished silicon surface. Since regular steel used for injection molding tools is not a perfect material with grain boundaries and large local variation in the material composition the best quality of the sub-micrometer structures are obtained if these structures are transferred into a more uniform material coated onto the insert surface to be structured. For this we have demonstrated the use of electro chemically deposited $\mathrm{Ni}$, and sputtered $\mathrm{CrN}$. It has been tested to transfer the pattern into regular steel and it was proven to give a very poor pattern definition. Thus, work is also on-going to develop a new type of steel, called "advanced steel" with a much better uniformity suitable for pattern transfer directly into the steel. Even though this is not always desirable, because many injection molding inserts are covered with a hard coating to extend the lifetime of the inserts, which would bury any sub-micrometer structures made on the surface prior to the coating, we want to be able to offer all possibilities and steel with a better uniformity could also be harder than regular steel so the hard coating would not be required on advanced steel. The advantage of the electro chemically deposited $\mathrm{Ni}$ is that the process in itself has planarizing capabilities so it can help reduce the roughness on the insert before imprinting but as shown in section 3 the lifetime of inserts with $\mathrm{Ni}$ is not as good as required for injection molding inserts used for high volume production. On top of the insert an imprint resist, thermo plastic or UV curable, is applied by spray coating or when possible spin coating. To imprint sub-micrometer patterns thin resist coatings, typically from $100 \mathrm{~nm}$ to $200 \mathrm{~nm}$ thick, are required, which is challenging to obtain with spray coating. Work is on-going to solve this by changing the chemical formulation of the resists to make them more suitable for spray coating. At the moment the best quality resist film and thereby pattern transfer is obtained with spin-coated resist, which has proven to work with good results on planar, convex and concave inserts by optimizing the amount of solvent in the resist for each insert geometry. The flexible mold is used in a home built imprint tool to imprint the desired pattern into the imprint resist. In the release after imprinting a lot of efforts have been put into avoiding rip-off issues degrading the quality of the imprinted pattern. Specially two types of rip-off effects were observed before optimization. Small area rip-offs as shown in Figure 3.a was mainly avoided by improving the surface quality of the inserts and optimizing the resist thickness. Large area rip-offs as shown in Figure 3.b have been solved by improving the resist treatment before imprint, specially prebake time has shown to play a significant role. Additionally imprint parameters as imprint temperature, imprint time and release temperature were adjusted. After optimization of above mentioned parameters, it was possible to achieve a high quality imprint of the optical diffractive grating pattern as shown in Figure 3.c.
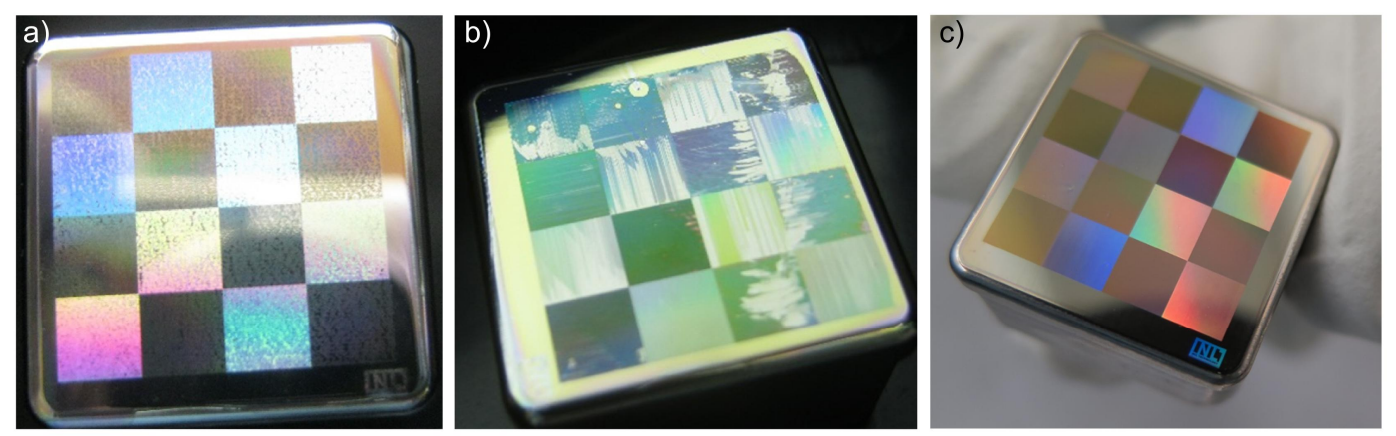

Figure 3. Optimization of imprinting on inserts; a) Image showing small area rip-offs, b) Image showing large area rip-offs, c) Sub-micrometer patterned injection molding insert after optimization of the imprint process.

After imprinting the pattern is transferred directly into the insert surface by a dry unidirectional sputter etching process. The residual layer after imprinting is not removed before etching so the process relies on the sputter etch going through 
the residual layer before it starts to etch into the surface. Typical etch depths at present are $100 \mathrm{~nm}$ to $200 \mathrm{~nm}$, work are on-going to increase this. After etching, the insert is cleaned and is then ready for injection molding. Figure 4 shows an image and a representative SEM and AFM of a planar insert after cleaning.
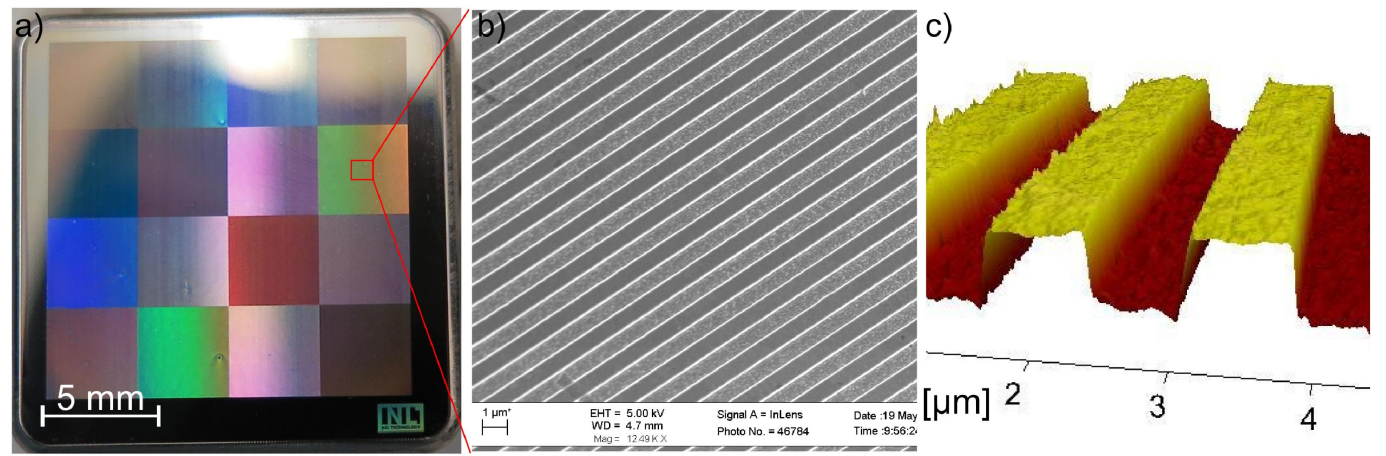

Figure 4. Final planar injection molding insert with structured optical diffraction gratings; a) Insert after imprint, pattern transfer and cleaning, b) Representative SEM of one of the etched grating patterns, c) Representative AFM of the $120 \mathrm{~nm}$ deep etched grating trenches on the insert.

\section{INSERT LIFETIME INVESTIGATIONS}

The lifetime of the sub-micrometer line gratings have been tested by running injection molding series of 102,000 and 73,000 shots, respectively, by the use of two different inserts. The first insert was prepared with electrochemically deposited $\mathrm{Ni}$ on the surface and the second insert was an advanced steel insert with the optical diffraction grating transferred directly into the steel surface. Figure 5 shows an image of the Ni coated insert before and after the 102,000 shots together with a representative SEM of the degraded areas on the insert. Many of the injection molded parts throughout the series of 102,000 parts have been inspected by optical diffraction microscopy using an adapted commercial light microscope with two detectors, a CCD camera and a spectrometer ${ }^{8}$ to monitor the structure degradation process. The inspection data shows that the degradation is a gradual process so the structures in $\mathrm{Ni}$ are not persevering enough to survive many injection molding cycles. Figure 6 shows a representative SEM of the advanced steel insert before and after 73,000 injection molding cycles together with images of injection molded parts 1 and 73,000 and an AFM of the $700 \mathrm{~nm}$ pitch linegrating on the insert after 73,000 cycles. As one can see there are no indications of structure degradation on this insert so sub-micrometer structures in advanced steel is suitable for production of parts by injection molding.
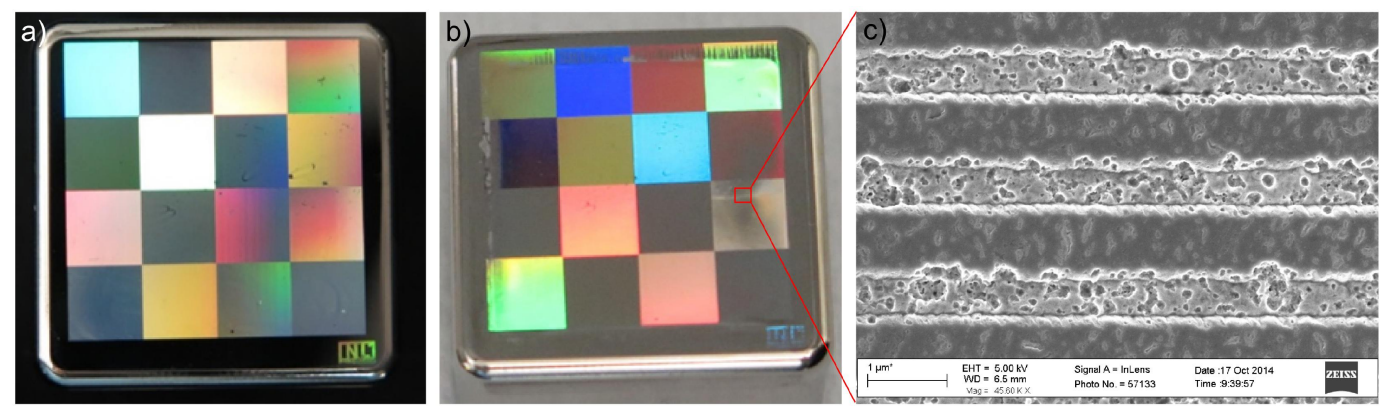

Figure 5. Lifetime test with Ni coated steel insert; a) Insert before injection molding, b) Insert after injection molding of 102,000 parts, c) Example SEM of degraded parts of the insert after injection molding of 102,000 parts. 

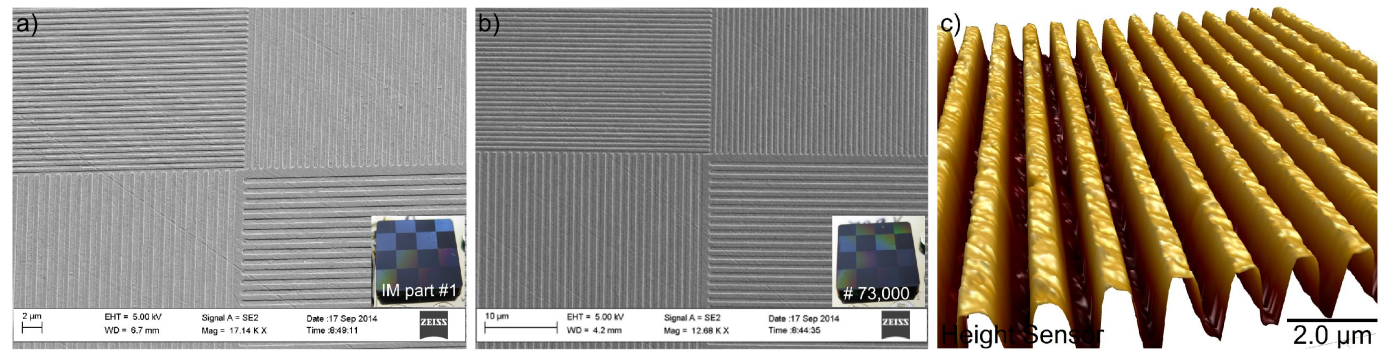

Figure 6. Lifetime test with advanced steel insert; a) Representative SEM of insert before injection molding (insert: injection molded part \#1), b) Representative SEM of insert after injection molding of 73,000 parts (insert: injection molded part \#73,000), c) Representative AFM of well-preserved $700 \mathrm{~nm}$ pitch line grating after injection molding of 73,000 parts. The measured height across the insert span from $90 \mathrm{~nm}$ for the $700 \mathrm{~nm}$ pitch lines to $120 \mathrm{~nm}$ for the $1400 \mathrm{~nm}$ pitch lines.

\section{ULTIMATE RESOLUTION}

For decoration by plasmonic colors and for some approaches to make super-hydrophobic and self-cleaning surfaces as well as more advanced applications within among others the biotech and pharma sectors smaller and denser structures than $700 \mathrm{~nm}$ pitch linegratings are required. For plasmonic color decoration work is on-going to identify the ultimate resolution of the steel insert structuring technology. Figure 7 shows the densest two-dimensional grating that so far has been successfully structured on large area with high fidelity on a steel insert. The hole size is $140 \mathrm{~nm}$ with a pitch of $300 \mathrm{~nm}$ in a square arrangement. The hole depth measured by AFM is $50 \mathrm{~nm}$. Also down to $100 \mathrm{~nm}$ wide holes with a pitch of $200 \mathrm{~nm}$ in square arrangement have been demonstrated but work is still ongoing to increase the fidelity of such dense and small structures on steel inserts.
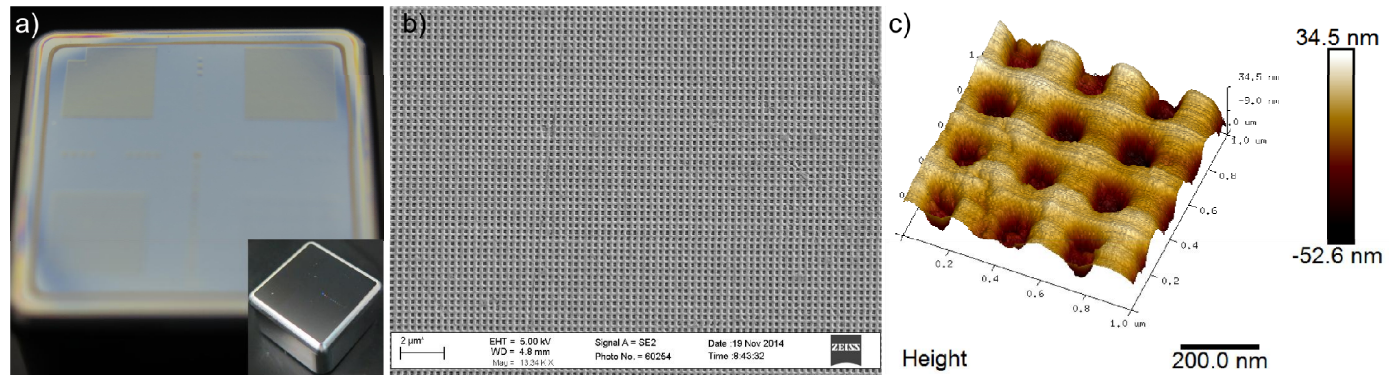

Figure 7. Nano patterned advanced steel insert; a) Steel insert after imprint. Insert image shows the result after pattern transfer, b) SEM of the $140 \mathrm{~nm}$ holes with a pitch of $300 \mathrm{~nm}$, square arrangement, c) Representative AFM image of the $140 \mathrm{~nm}$ wide holes showing an etch depth of $50 \mathrm{~nm}$.

\section{CONCLUSION}

Structuring of injection molding inserts on the sub-micrometer scale has been demonstrated using an optical diffraction line grating pattern. The technology is applicable for structuring steel inserts made in advanced steel or regular steel with $\mathrm{Ni}$ or $\mathrm{CrN}$ coatings. The ultimate resolution capabilities of this technology has so far been demonstrated to be $140 \mathrm{~nm}$ wide holes with a pitch of $300 \mathrm{~nm}, 50 \mathrm{~nm}$ deep. Plastic parts have been injection molded from the structured inserts using standard injection molding processes. The plastic parts have been evaluated by SEM, AFM and optical diffraction microscopy to confirm the pattern fidelity. A durability test have been made showing that an insert with optical diffraction linegratings defined in a Ni coating is not suitable for injection molding since the structures in the Ni coating gradually degrades during the 102,000 injection molding cycles made with it. A similar insert made in advanced steel shows no degradation after 73,000 injection molding cycles. 


\section{ACKNOWLEDGEMENTS}

This work was supported by InnovationsFonden (NanoPlast, grant no: 007-2010-2) and from the European

Community's Seventh Framework Programme (Plast4Future, grant no: 314345).

\section{REFERENCES}

[1] Feng, L., Li, S., Li, Y., Li, H., Zhang, L., Zhai, J., Song, Y., Liu, B., Jiang, L., Zhu, D. "Super-Hydrophobic Surfaces: From Natural to Artificial," Adv. Mater. 24, 1857-1860 (2002)

[2] Jeong, H.E., Lee, J-K., Kwak, M.K., Moon, S.H., Suh, K.Y. "Effect of leaning angle of gecko-inspired slanted polymer nanohairs on dry adhesion," Appl. Phys. Lett. 96, 043704 (2010)

[3] Ball, P. "Shark skin and other solutions," Nature 400, 507-509 (1999)

[4] Clausen, J.S., Højlund-Nielsen, E., Christiansen, A.B., Yazdi, S., Grajower, M., Taha, H., Levy, U., Kristensen, A., Mortensen, N.A. "Plasmonic Metasurfaces for Coloration of Plastic Consumer Products," Nano Lett. 14, 4499-4504 (2014)

[5] Chou, S.Y., Krauss, P.R., Renstrom P.J. "Imprint of sub-25 nm vias and trenches in polymers," Applied physics letters 21, 3114-3116 (1995)

[6] Sonne, M.R., Smistrup, K., Hannibal M., Thorborg J., Nørregaard J., Hattel J.H. "Modeling and simulation of the deformation process of PTFE flexiblestamps for nanoimprint lithography on curved surfaces," Journal of Materials Processing Technology 216, 418-429 (2015)

[7] Smistrup, K., Nørregaard, J., Mironov, A., Bro, T.H., Bilenberg, B., Nielsen, T., Eriksen, J., Thilsted, A.H., Hansen, O., Kristensen, A., Rishton, S., Khan, F., Emanuel, M., Ma, Y., Zhang, Y." Nanoimprinted DWDM laser arrays on indium phosphide substrates," Microelectronic Engineering 123, 149-153 (2014)

[8] Madsen, M.H., Hansen, P-E., Zalkovskij, M., Karamehmedovic, M., Garnæs, J. "Fast Characterization of Moving Samples with Nano-Textured Surfaces," Submitted to Optica (2015), http://arxiv.org/abs/1501.05793 